\title{
PENDIDIKAN LITERASI MEDIA UNTUK GURU-GURU SMK MUHAMMADIYAH 2 PEKANBARU
}

\author{
Jupendri*, Jayus, Desliana Dwita, Fitria Mayasari \\ Ilmu Komunikasi, Fakultas Ilmu Komunikasi \\ Universitas Muhammadiyah Riau \\ email: jupendri@umri.ac.id
}

\begin{abstract}
The rapid development of television stations in Indonesia has influenced various aspects of people's lives such as among school students like in SMK Muhammadiyah 2 Pekanbaru. Various aspects influenced include social, cultural, religious, health and service quality. Social reality or the negative impact of the presence of mass media especially television does get the attention of parents and teachers. Media literacy education is one of the efforts to develop skills in selecting and watching critically the programs presented by the media. Media education or media literacy is an activity that can help people to have the competence, ability, or skill needed to not reactive in a negative sense, but proactive in understanding the messages conveyed by the media. Educators are the right audience for media literacy education. In an effort to provide understanding to school students in choosing, understanding and sorting media messages, especially television media. For that done community service activities in the form of Media Literacy Education For Teachers in SMK Muhammadiyah 2 Pekanbaru. The results of this activity, teachers in SMK Muhammadiyah 2 become more familiar about media literacy, and able to provide direction and understanding of the contents of the media so that learners become critical and creative.
\end{abstract}

Keywords: Media literacy, Teachers, SMK Muhammadiyah 2

\begin{abstract}
Abstrak
Pesatnya perkembangan stasiun televisi di Indonesia telah mempengaruhi berbagai aspek dalam kehidupan masyarakat diantaranya pada kalangan siswa-siswi sekolah seperti di SMK Muhammadiyah 2 Pekanbaru. Berbagai aspek yang dipengaruhi meliputi sosial, budaya, religi, kesehatan dan mutu pelayanan. Realitas sosial atau dampak negatif kehadiran media massa khususnya televisi memang mendapatkan perhatian dari orang tua dan guru. Pendidikan literasi media merupakan salah satu upaya untuk menumbuhkan kecakapan dalam memilih dan menonton secara kritis program-program yang disajikan oleh media. Pendidikan media atau disebut dengan literasi media merupakan kegiatan yang dapat membantu orang untuk memiliki kompetensi, kemampuan, atau kecakapan yang dibutuhkan agar tidak reaktif dalam arti negatif, namun proaktif dalam memahami pesan-pesan yang disampaikan media. Kalangan pendidik merupakan khalayak yang tepat untuk diberikan pendidikan literasi media. Sebagai upaya memberikan pemahaman kepada siswa-siswi sekolah dalam memilih, memahami dan memilah pesan media, khususnya media televisi. Untuk itu dilakukan kegiatan pengabdian masyarakat berupa Pendidikan Literasi Media Untuk Guru-Guru SMK Muhammadiyah 2 Pekanbaru. Hasil kegiatan ini, guru-guru di SMK Muhammadiyah 2 menjadi lebih paham mengenai literasi media, dan mampu memberikan pengarahan dan pemahaman mengenai isi media sehingga peserta didik menjadi kritis dan kreatif.
\end{abstract}

Kata kunci : Literasi Media, Guru, SMK 2 Pekanbaru 


\section{PENDAHULUAN}

Secara historis, perkembangan media massa sejak keberadaannya sekitar tahun 1830-an terus mengalami perubahan secara significant, disebabkan kehadiran teknologi komunikasi dan informasi yang semakin mutakhir. Perkembangan tersebut diawali dari lahirnya surat kabar penny press, diikuti dengan kehadiran buku yang dipasarkan secara massa sekitar tahun 1800-an. Kemudian tahun 1900-an hadirlah televisi yang menggabungkan berita, hiburan, gambar bergerak dan suara, memasuki rumah-rumah dan semuanya kelihatan gratis tanpa bayar (Baran, 2012:49).

Berkaitan dengan televisi, mutu siarannya selalu menjadi perhatian dan pembicaraan dalam berbagai diskusi. Biasanya muncul pendapat yang menghendaki acara televisi yang bermutu dan bernilai positif bagi pendidikan masyarakat. Namun persoalannya, televisi jauh lebih mengunggulkan popularitas sebuah acara dibandingkan dengan berupaya untuk memberikan tontonan yang dinilai bermuatan positif bagi pendidikan dan pengetahuan khalayak. Popularitas televisi yang ditonton oleh banyak orang didasarkan pada rating kepemirsaan. Orientasi sistem rating, merujuk kepada aspek kuantitatif sebagai patokan untuk mengukur tingkat popularitas sebuah acara televisi (Susanto, 2009:107).

Keberadaan media massa khususnya televisi telah mempengaruhi berbagai aspek dalam kehidupan masyarakat. Berbagai aspek yang dipengaruhi meliputi sosial, budaya, religi, dan kesehatan. Pertama, aspek sosial. Televisi sebagai sebuah media komunikasi mempunyai pengaruh terhadap tingkah laku penonton (khalayak). Pengaruh itu terjadi bila terdapat perubahan pada prilaku nyata yang dapat diamati, meliputi pola-pola tindakan, kegiatan atau kebiasaan prilaku.

Ada kecenderungan meningkatnya tindak kekerasan dan perilaku negatif pada siswa di sekolah lanjutan tingkat atas Muhammadiyah Pekanbaru, seperti perkelahian dan ugal-ugalan di jalan raya seperti pada perpisahan sekolah. Maraknya program hiburan di televisi seperti sinetron remaja yang seringkali mengandung unsur kekerasan dan perilaku negatif, dianggap sebagai salah satu pemicu munculnya tindak kekerasan tersebut.

Tayangan remaja di televisi saat ini seringkali telah melanggar standar program siaran yang layak, namun seringkali juga diabaikan oleh stasiun televisi yang bersangkutan. Mengutip dari situs resmi Komisi Penyiaran Indonesia (kpi.go.id), sepanjang tahun 2013 sampai dengan April 2014, KPI menerima sebanyak 1600-an pengaduan masyarakat terhadap program sinetron dan FTV yang dianggap meresahkan dan membahayakan pertumbuhan fisik dan mental anak serta mempengaruhi perilaku kekerasan terhadap anak.

Kedua, aspek budaya. Televisi mempengaruhi budaya dalam berbagai macam cara yang tak terhitung jumlahnya. Salah satu pengaruhnya pada siswa-siswi di sekolah lanjutan tingkat atas Muhammadiyah Pekanbaru, adalah memudarnya budaya gotong royong dan rajin belajar. Budaya rajin belajar dan gotong royong berubah menjadi malas belajar. Acara televisi yang menarik dan menghibur lebih dipilih siswa dibandingkan dengan belajar.

Ketiga, aspek religi dan kesehatan. Pada aspek ini aspek religi (keagamaan) dan kesehatan para siswa 
dipengaruhi oleh media massa seperti televisi. Para siswa di sekolah lanjutan tingkat atas Muhammadiyah Pekanbaru meliputi SMK Muhammadiyah 2 cenderung mengutamakan menonton televisi dibandingkan melakukan ibadah dan menjaga kesehatan. Bahkan tak jarang para siswa menahan rasa lapar, disebabkan keasyikan menonton televisi.

Realitas sosial atau dampak negatif kehadiran media massa khususnya televisi memang mendapatkan kecaman dari orang tua dan guru. Akan tetapi hanya sebatas mengecam (menyampaikan) dan tidak berperan langsung dalam proses komunikasi massa. Masyarakat (khususnya para orang tua) memiliki kecakapan penafsiran dan pemahaman tingkat tinggi, yang membuatnya dapat memahami dan menikmati acara televisi, film atau cerita dalam majalah bahkan yang rumit sekalipun. Namun, belum maksimal berperan dalam memberikan edukasi kepada anak sehingga dampak negatif dapat dihindari.

Pendidikan literasi media kemudian menjadi penting dilakukan mengingat perkembangan media massa yang begitu cepat serta efek yang diberikannya pada anak didik. Oleh sebab itu perlu peran semua pihak diantaranya para pendidik atau guruguru untuk senantiasa mengingatkan siswa siswinya.

Pendidikan literasi media merupakan salah satu upaya untuk menumbuhkan kecakapan dalam memilih dan menonton secara kritis terhadap program-program yang disajikan oleh media. Pendidikan media atau dalam lingkup yang lebih khusus disebut dengan literasi media merupakan kegiatan yang dapat membantu seseorang untuk memiliki kompetensi, kemampuan, atau kecakapan yang dibutuhkan agar tidak reaktif dalam arti negatif, namun proaktif dalam memahami pesan-pesan yang disampaikan media.

Untuk menciptakan khalayak aktif dari kalangan anak muda, perlu dilakukan pendidikan literasi media dalam upaya mengembangkan pemahaman kritisnya. Kalangan pendidik merupakan khalayak yang tepat untuk diberikan pendidikan literasi media. Berdasarkan permasalahan diatas, maka dirasa perlu memberikan Pendidikan Literasi Media Untuk Guru-Guru SMK Muhammadiyah 2 Pekanbaru.

\section{METODE PENGABDIAN}

Metode yang dilakukan dalam Pengabdian kepada Masyarakat ini adalah metode ceramah, diskusi, tanya jawab serta penayangan video. Diawali dengan pemberian materi tentang konsep literasi media, fungsi literasi media, fenomena isi media, dan media parenting. Dilanjutkan dengan diskusi dan tanya jawab.

\section{HASIL DAN PEMBAHASAN}

Kegiatan dilakukan di SMK Muhammadiyah 2 yang berada di Jalan KH. Ahmad Dahlan, Kelurahan Sukajadi, Kecamatan Sukajadi Kota Pekanbaru. Peserta yang hadir terdiri dari Kepala Sekolah, Waka Kurikulum, Waka Kesiswaan, Waka Humas, Waka Sapras, Waka Ismuba, para guru, Guru Bimbingan Konseling serta Tata Usaha di lingkungan SMK Muhammadiyah 2 Pekanbaru. Jumlah peserta yang hadir dalam kegiatan pengabdian sekitar 49 orang.

Acara dilaksanakan pada hari Jumat tanggal 23 Februari 2018 mulai pukul 14.00 WIB hingga pukul 16.30 WIB. Pemateri terdiri dari 4 orang dosen prodi Ilmu Komunikasi Universitas Muhammadiyah Riau, yaitu Jupendri, 
S.Sos, M.I.Kom, Jayus, S.Sos, M.I.Kom, Desliana Dwita, S.IP, M.I.Kom, dan Fitria Mayasari, S.I.Kom, MA.

Kegiatan pendidikan lliterasi media bagi Guru-Guru SMK Muhammadiyah 2 Pekanbaru, memperdalam pengetahuan para guru akan literasi media dan media parenting.

Literasi media (melek media) merupakan pengetahuan dan keterampilan individu menganalisis, mengevaluasi, atau menghasilkan pesan dari media yang dilihat, dibaca ataupun di dengar.

Pengetahuan tersebut berupa pengetahuan tentang isi media, seperti judul acara $\mathrm{TV}$, nama tokoh dalam episode tertentu, judul buku, nama situs, dan sebagainya. Keterampilan terkait dengan kemampuan memahami berbagai teknis penceritaan, kemampuan bermain video games, kemampuan mengakses internet, menggunakan komputer, dan sebagainya.

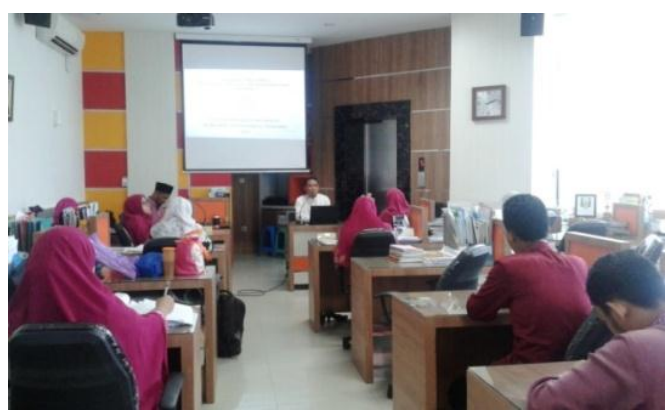

Gambar 1. Penyampaian materi oleh pelaksana pengabdian

Tujuan literasi media adalah untuk mengeksplorasi pertanyaan-pertanyaan yang muncul ketika orang terlibat kritis dengan pesan-pesan yang termediasi baik cetak maupun elektronik. Media literacy dicirikan oleh prinsip penyelidikan yaitu, belajar untuk mengajukan pertanyaan penting tentang apa pun yang dilihat, ditonton, didengar, dan dibaca.
Terdapat tiga pilar yang membentuk literasi media. Antara lain:

1. Personal locus; terdiri atas tujuan dan dorongan. Locus merupakan kombinasi antara kesadaran terhadap tujuan, dorongan, dan energi yang mengarahkan kepada pencarian informasi. Locus beroperasi dalam dua bentuk: sadar dan tak sadar.

2. Kedua, struktur pengetahuan, yakni seperangkat informasi yang terorganisiasi dalam memori seseorang dan terbentuk secara sistematis dalam waktu yang lama. Struktur membantu kita melihat pola. Semakin banyak struktur pengetahuan yang kita miliki, maka kita semakin percaya diri dalam memaknai berbagai pesan media.

3. Ketiga, keterampilan (skill). Keterampilan ini akan berkembang seperti halnya dengan otot dalam tubuh manusia bila sering dilatih. Ada tujuh keterampilan dalam konteks literasi media, yaitu: keahlian untuk menganalisis, mengevaluasi, memilah, menginduksi, mendeduksi, mensintesis, dan mengabstraksis pesan-pesan media.

Siaran televisi nasional Indonesia saat ini banyak memberi dampak negatif. Menurut data Komisi Penyiaran Indonesia, tingkat pelanggaran televisi pada tahun 2017 cukup tinggi. Persaingan televisi yang semakin ketat membuat perusahaan televisi berusaha membuat program acara yang menarik tanpa memperhatikan hukum dan etika penyiaran.

Beberapa program acara remaja yang pernah ditegur Komisi Penyiaran Indonesia (KPI) diantaranya sinetron 'Siapa Takut Jatuh Cinta' yang ditayangkan oleh stasiun SCTV pada tanggal 27 November 2017 mulai 
pukul 18.00 WIB. Menurut KPI melalui kpi.go.id, program siaran tersebut menayangkan adegan seorang pria berjaket biru seakan sedang mencium bibir wanita berpakaian hijau. KPI Pusat menilai muatan tersebut tidak layak ditampilkan, terutama pada khalayak remaja. Jenis pelanggaran ini dikategorikan sebagai pelanggaran atas ketentuan tentang norma kesopanan dan kesusilaan, perlindungan remaja, pelarangan adegan yang mengesankan ciuman bibir, dan penggolongan program siaran.

Melihat terdapat program siaran yang dapat memberi dampak negatif bagi remaja, maka guru SMK diharapkan dapat memberikan pengetahuan kepada siswa-siswi untuk kritis dan pandai memilih tayangan yang bermanfaat yang disebut dengan melek media.

Setelah penyampaian materi selesai diberikan oleh masing-masing pemateri, sesi tanya jawab dibuka. Beberapa guru di SMK Muhammadiyah 2 Pekanbaru mengajukan pertanyaan kepada para pemateri. Pertanyaan yang diajukan berkaitan dengan upaya yang dilakukan ketika menemukan adanya pelanggaran konten media yang tidak sesuai dengan P3 dan SPS. Pertanyaan yang diajukan juga berhubungan dengan cara pendampingan yang tepat dalam menumbuhkan kemampuan literasi media siswa.

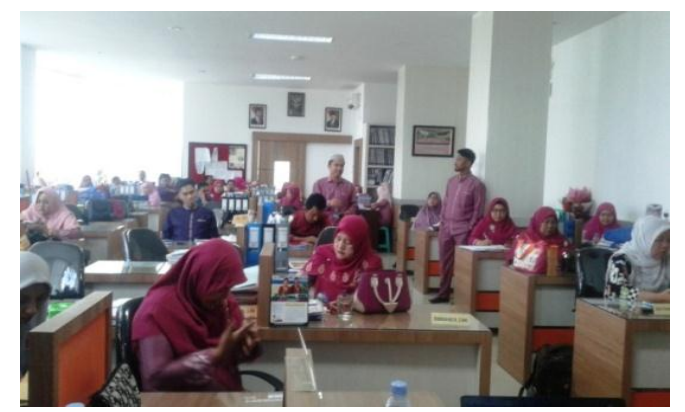

Gambar 2. Sesi tanya jawab antara peserta dan pelaksana pengabdian

\section{KESIMPULAN}

Kemampuan literasi media harus dimiliki khalayak media ditengah fenomena media saat ini. Literasi media diperlukan agar dapat memanfaatkan media secara tepat baik sebagai sumber informasi, pendidikan maupun hiburan. Peningkatan pemahaman literasi media guru-guru merupakan hal penting agar dapat mengarahkan siswa-siswi untuk memiliki kecakapan dalam memilih dan menonton secara kritis terhadap program-program yang disajikan oleh media.

Dengan memiliki kemampuan literasi media, khalayak media tidak hanya sekedar mampu memahami isi pesan media. Ada kecakapankecakapan khusus yang harus dimiliki dalam mengkonsumsi media. Antara lain, kemampuan dan keinginan untuk memahami, memberi perhatian dan menyaring noise. Pemahaman tentang kekuatan isi media juga merupakan kecakapan yang harus dimiliki, serta kemampuan untuk membedakan reaksi emosional dan reaksi logis ketika merespon isi media dan bertindak di dalamnya.

\section{UCAPAN TERIMAKASIH}

Ucapan terima kasih disampaikan kepada:

1. Lembaga Penelitian dan Pengabdian Masyarakat (LPPM) Universitas Muhammadiyah Riau (UMRI) yang telah memberikan dukungan berupa biaya dan motivasi.

2. Fakultas Ilmu Komunikasi Universitas Muhammadiyah Riau yang telah memberi dukungan agar terselenggaranya kegiatan pengabdian kepada masyarakat ini.

3. Kepala Sekolah, Waka Kurikulum, Waka Kesiswaan, Waka Humas, Waka Sapras, Waka Ismuba, para 
guru, Guru Bimbingan Konseling serta Tata Usaha di lingkungan SMK Muhammadiyah 2 Pekanbaru

4. Seluruh peserta pelatihan, yaitu para guru SMK Muhammadiyah 2 Pekanbaru yang antusias dalam mengikuti kegiatan ini.

\section{DAFTAR PUSTAKA}

1. Ardianto, Elvinaro. 2009. Komunikasi Massa: Suatu Pengantar. Bandung: Simbiosa Rekatama

2. Baran, J. Stanley. 2012. Pengantar Komunikasi Massa. Jakarta: Erlangga

3. Lubis, Mila. 2017. Trend Baru di Kalangan Pengguna Internet di Indonesia. http://www.nielsen.com diakses pada 20 Februari 2018

4. Nielsen. 2014. Konsumsi Media Lebih Tinggi di Luar Jawa. Diakses melalui http://www.nielsen.com/id/en/pres s-room/2014/nielsen-konsumsimedia-lebih-tinggi-di-luarjawa.html pada tanggal 13 Maret 2018

5. Potter, W. James. 2014. Potter: Media Literacy. https://indonesiamedialiteracydotn et1.wordpress.com diakses pada 20 Februari 2018

6. Rahardjo, Turnomo, dkk. 2012. Literasi Media \& Kearifan Lokal: Konsep dan Aplikasi. Yogyakarta : Buku Litera

7. Rochimah, Tri Hastuti Nur dan Fajar Junaedi. 2013. Media Parenting Panduan Memilih Media Bagi Anak di Era Informasi. Yogyakarta: Buku Litera

8. Sasongko, Darmadi. 2012. KPI Terima 43.470 Pengaduan Siaran Televisi. Diakses dari https://www.kapanlagi.com/showb iz/televisi/kpi-terima-43470pengaduan-siaran-televisi- b97cbd.html tanggal 13 Maret 2018

9. Setiaman, Agus dan Slamet Mulyana. 2008. Perkembangan Media Massa dan Media Literasi di Indonesia, https://agussetiaman.wordpress.co $\mathrm{m} / 2008 / 11 / 07$ diakses pada 3 September 2015

10. Soebagijo, Azimah dan Idy Muzayyad. 2016. Literasi Media Televisi. Pekanbaru:Komisi Penyiaran Indonesia Daerah Riau

11. Susanto, Harry Eko. 2009. Komunikasi Politik dan Otonomi Daerah. Jakarta: Mitra Wacana Media

12. Tanti, Dewi Sad. 2011. Strategi Literasi Media Baru: Selancar di tengah Dinamika Teknologi dan Kondisi Sosial Politik, Paper disajikan di Universitas Muhammadiyah Surakarta

13. Teguran Tertulis untuk Program Siaran "Rumah Uya" Trans 7. 2017. http://www.kpi.go.id diakses pada 20 Februari 2018

14. Teguran Tertulis untuk Program Siaran "Siapa Takut Jatuh Cinta" SCTV. 2017. http://www.kpi.go.id diakses pada 20 Februari 2018 